\title{
High-sensitive cardiac Troponin T is superior to echocardiography in predicting 1-year mortality in patients with SIRS and shock in intensive care
}

\author{
Lill Bergenzaun ${ }^{*}$, Hans Öhlin², Petri Gudmundsson³ ${ }^{3}$ Joachim Düring ${ }^{4}$, Ronnie Willenheimer ${ }^{5}$ \\ and Michelle S Chew ${ }^{6}$
}

\begin{abstract}
Background: Left ventricular (LV) dysfunction is well documented in the critically ill. We assessed 1-year mortality in relation to cardiac biomarkers and LV function parameters by echocardiography in patients with shock.

Methods: A prospective, observational, cohort study of 49 patients. B-natriuretic peptide (BNP), high-sensitive troponin T (hsTNT) and transthoracic echocardiography (TTE) were assessed within $12 \mathrm{~h}$ of study inclusion. LV systolic function was measured by ejection fraction (LVEF), mean atrioventricular plane displacement (AVPDm), peak systolic tissue Doppler velocity imaging (TDIs) and velocity time integral in the LV outflow tract (LVOT VTI). LV diastolic function was evaluated by transmitral pulsed Doppler (E, A, E/A, E-deceleration time), tissue Doppler indices (é, á, E/é) and left atrial volume (La volume). APACHE II (Acute Physiology and Chronic Health Evaluation) and SOFA (Sequential Organ Failure Assessment) scores were calculated.

Results: hsTNT was significantly higher in non-survivors than in survivors (60 [17.0-99.5] vs 168 [89.8-358] ng/l, $p=0.003)$. Other univariate predictors of mortality were APACHE II $(p=0.009)$, E/é $(p=0.023)$, SOFA $(p=0.024)$ and age $(p=0.031)$. Survivors and non-survivors did not differ regarding BNP $(p=0.26)$ or any LV systolic function parameter (LVEF $p=0.87$, AVPDm $p=0.087$, TDIs $p=0.93$, LVOT VTI $p=0.18$ ). Multivariable logistic regression analysis identified hsTNT $(p=0.010)$ as the only independent predictor of 1-year mortality; adjusted odds ratio $2.0(95 \% \mathrm{Cl} 1.2-3.5)$.

Conclusions: hSTNT was the only independent predictor of 1-year mortality in patients with shock. Neither BNP nor echocardiographic parameters had an independent prognostic value. Further studies are needed to establish the clinical significance of elevated hsTNT in patients in shock.
\end{abstract}

Keywords: Echocardiography, BNP, High-sensitive TNT, Myocardial function, Mortality, Shock

\section{Background}

Myocardial depression is a well-known complication of septic shock [1,2]. Raised levels of cardiac biomarkers such as natriuretic peptides $[3,4]$ and cardiac troponin (cTn) [5], as well as echocardiographic changes of LV function [6-8] are frequently described. cTn is highly useful for both diagnosis and prognostication in patients with cardiac disease $[5,9]$. The recent introduction of a

\footnotetext{
* Correspondence: lill.bergenzaun@skane.se

'Department of Anaesthesiology and Intensive Care, Institution of Clinical Sciences, Skåne University Hospital, Lund University, Inga Marie Nilssons gata 47, S-20502 Malmö, Sweden

Full list of author information is available at the end of the article
}

new generation of high sensitivity assays for cTn with lower cut-off values suggests advantages over traditional cTn in terms of accuracy [10], diagnosis [11] and prognostication $[11,12]$ in patients with cardiac disease as well as in the general population [13]. In intensive care patients elevated cTN is related to mortality [14-16] and one study showed that hsTNT correlated to the severity of disease and was significantly higher in hospital nonsurvivors compared to survivors [17].

Elevated levels of natriuretic peptides such as B-natriuretic peptide (BNP) and amino- terminal fragment of BNP (NT-proBNP) are known to be strong prognostic markers in patients with cardiovascular disease

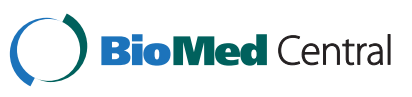


$[18,19]$. In the critically ill raised levels of BNP and NTproBNP can be found in many patients for a variety of reasons [20] and can be used as prognostic indicators $[21,22]$. Echocardiography is regarded useful for assessing cardiac function [23] but there are conflicting data regarding the prognostic value of LV systolic and diastolic function in patients in the intensive care unit (ICU) $[3,4,24,25]$. We investigated well established parameters of LV systolic [26-29] and diastolic function [30], where the latter have gained interest in ICU populations during the recent years $[3,25]$.

The aim of this study was to investigate whether hsTNT, BNP and echocardiographic parameters of LV function measured within $12 \mathrm{~h}$ are associated with 1year mortality in patients with shock.

\section{Methods}

The study was approved by the Regional Ethics Review Board, Lund, Sweden (Dnr.187/2005). Informed consent was sought from the patient or, if not possible, from the next of kin. The study design was a prospective observational cohort study. Patients $>18$ years old admitted to the mixed-bed ICU of Skåne University Hospital, Malmö, Sweden, were screened for eligibility. We included 55 consecutive patients with Systemic Inflammatory Response Syndrome (SIRS) and shock, defined as failure to maintain mean arterial pressure $\geq 70 \mathrm{mmHg}$, despite adequate fluid resuscitation according to the surviving sepsis campaign algorithm [31]. Exclusion criteria were pregnancy, pre-existing abnormalities of coagulation, fibrinolytic therapy, compromised immunity or a "Do Not Attempt Resuscitation" order. Patients could only be included once. This study was part of a larger project over a 7 day period investigating other aspects of critical illness [32] independent of our study aim. APACHE II scores [33] were calculated at admission and SOFA scores [34] were calculated after $24 \mathrm{~h}$. After the initial resuscitation period, fluids were given at the treating clinician's discretion.

\section{Biochemical analyses}

Blood samples were taken from an indwelling arterial line within $12 \mathrm{~h}$ of inclusion. They were sent to the local clinical chemistry laboratory, Skåne University Hospital, Malmö, Sweden, where they were centrifuged, frozen at $-80^{\circ} \mathrm{C}$ and stored. hsTNT was measured using immunoassay (Cobas e601, Roche Diagnostics GmbH, Penzberg, Germany) [10]. The measuring range is $3-10$ $000 \mathrm{ng} / \mathrm{L}$ and the upper reference limit $\left(99^{\text {th }}\right.$ percentile) is $14 \mathrm{ng} / \mathrm{l}$ in healthy volunteers. The inter-assay coefficient of variation $(\mathrm{CV})$ was $<10 \%$. Plasma BNP levels were analysed using UniCel ${ }^{\mathrm{TM}}$ DxI 800 Beckman Access ${ }^{\circledR} \mathrm{Im}$ munoassay System (Beckman-Coulter Chaska, Brea, U.S.A.). The measuring range is $0.29-1445 \mathrm{pmol} / \mathrm{l}$ and the upper reference limit is $30 \mathrm{pmol} / \mathrm{l}$. The inter-assay $\mathrm{CV}$ was $<10 \%$. Biochemical samples were coded before analysis and laboratory personnel were blinded to clinical and echocardiographic data.

\section{Transthoracic echocardiography (TTE)}

TTE examinations were performed within $12 \mathrm{~h}$ hours of inclusion by either of four experienced echocardiographers (LB, MC, PG, MD). Images were acquired using a Hewlett- Packard Sonos 5500 (Andover, Mass, U.S.A) scanner and a $3 \mathrm{MHz}$ transducer. Two-dimensional (2D) imaging examinations were performed in the standard apical four- and two- chamber views (2C-and $4 \mathrm{C}$ views). Tissue harmonic imaging was used to enhance 2D image quality. Parameters of LV systolic function (LV ejection fraction [LVEF], mean atrioventricular plane displacement $[\mathrm{AVPDm}]$, peak systolic tissue Doppler velocity imaging [TDIs] and velocity time integral in the LV outflow tract [LVOT VTI]) were acquired as described previously [35]. Transmitral velocities were measured with pulsed-wave Doppler (PW) in the $4 \mathrm{C}$ view. For LV diastolic function, we used La volume and from the mitral inflow profile, the E- and A- velocity and E-deceleration time was measured. PW tissue Doppler recorded the diastolic velocities (é, á) of the LV septal wall at the level of the mitral annulus in the apical $4 \mathrm{C}$ view [36]. The E/A ratio as well as the E/é ratio, an index of LV filling pressure, were calculated [30]. La volume was estimated in the 4C view [37] and indexed to body surface area [30]. All TTE studies were recorded over three consecutive cardiac cycles independently of the respiratory cycle and averaged. In patients with non-sinus rhythm measurements were collected over 5-10 heartbeats. Analyses of the measurements were made $>16$ weeks after the data acquisition when the reader was less aware of the diagnosis in Phillip's digital storing program Xcelera (Best, the Netherlands) offline.

\section{Statistical analysis}

Data are presented as median (inter-quartile range $[I Q R])$, percentages or absolute values. For not normally distributed variables we used non-parametric test exclusively. For correlation between two variables, Spearman's rank correlation was used and for differences between two groups we used Mann-Whitney's $U$-test. Categorical data were analyzed with Fisher's exact test. HsTNT and BNP were log transformed with natural logarithm due to skewed distribution. Receiver operating characteristics (ROC) were used to define optimal cut-off values using the maximal area under the curve (AUC). Our aim was to investigate how 1-year mortality can be predicted by more than one explanatory variable measured early during ICU stay. Since we did not have any censored data during this period and odds ratio was the outcome of 
interest, logistic regression was chosen to be the most suitable method [38,39]. Multivariate (backward stepwise selection method with probability for the removal of $0.10)$ logistic regression analyses were used to determine the association of variables with 1-year mortality. Factors predictive of 1-year survival in univariate analyses were hsTNT, APACHE II, SOFA, E/é and age. As APACHE II score, but not SOFA score, is a validated general riskprognostication system we used it in our logistic regression [40]. Additionally we performed a multivariate logistic regression with creatinine, as a marker of renal dysfunction, and pre-existing cardiac disease including atrial fibrillation. Odds ratios (OR) were calculated. The relationship between hsTNT quartiles and mortality was investigated by logistic regression. The intra- and interobserver variability of echocardiographic parameters was measured by the $\mathrm{CV}$. CV was defined as the ratio of the standard deviation to the mean multiplied by 100 . All probability values are two-tailed and significance was set at $\mathrm{p}<0.05$. The analyses were performed using SPSS 18.0 (SPSS, Chicago, IL, U.S.).

\section{Results}

The original study included 55 consecutive patients. Two patients were excluded due to lack of written consent. One patient died $4 \mathrm{~h}$ after study inclusion and before echocardiographic examination, one patient was too obese to allow TTE and one patient was incorrectly registered in the echocardiography database. One patient moved abroad after 6 months, which precluded longerterm follow-up. These six patients were excluded from statistical analysis, resulting in a total of 49 analysed patients. Two-thirds of the population suffered from septic shock. The remaining patients suffered from shock due to other causes (pancreatitis, post-major noncardiac surgery, intoxication and multiorgan failure, gastrointestinal bleeding and portal hypertension or unknown cause). Pre-existing cardiac disease was present in $24 \%$ of patients, defined as severe arrhythmia, heart failure or ischemic heart disease. Norepinephrine was used as a vasopressor. Twelve patients received dobutamine and one adrenaline at inclusion. Ten patients received levosimendan during the study period. In all, $49 \%$ had pre-existing treatment with $\beta$ blockers, ACE-inhibitors, Ca-channel blockers, and/or nitrates.

\section{Biochemical cardiac markers}

HsTNT was detectable in all 49 patients, ranged from $<5$ to $2592 \mathrm{ng} / \mathrm{l}$ (median $80 \mathrm{ng} / \mathrm{l}$ [IQR 24.0-193.5]) and was elevated $(>14 \mathrm{ng} / \mathrm{l})$ in $45(92 \%)$ patients. With regard to 1-year mortality, AUC for hsTNT was 0.76 (95\% CI 0.612 - $0.907, \mathrm{p}=0.004$ ), with $72 \%$ sensitivity and $82 \%$ specificity for a cut-off value of $117.5 \mathrm{ng} / \mathrm{l}$ (Figure 1).

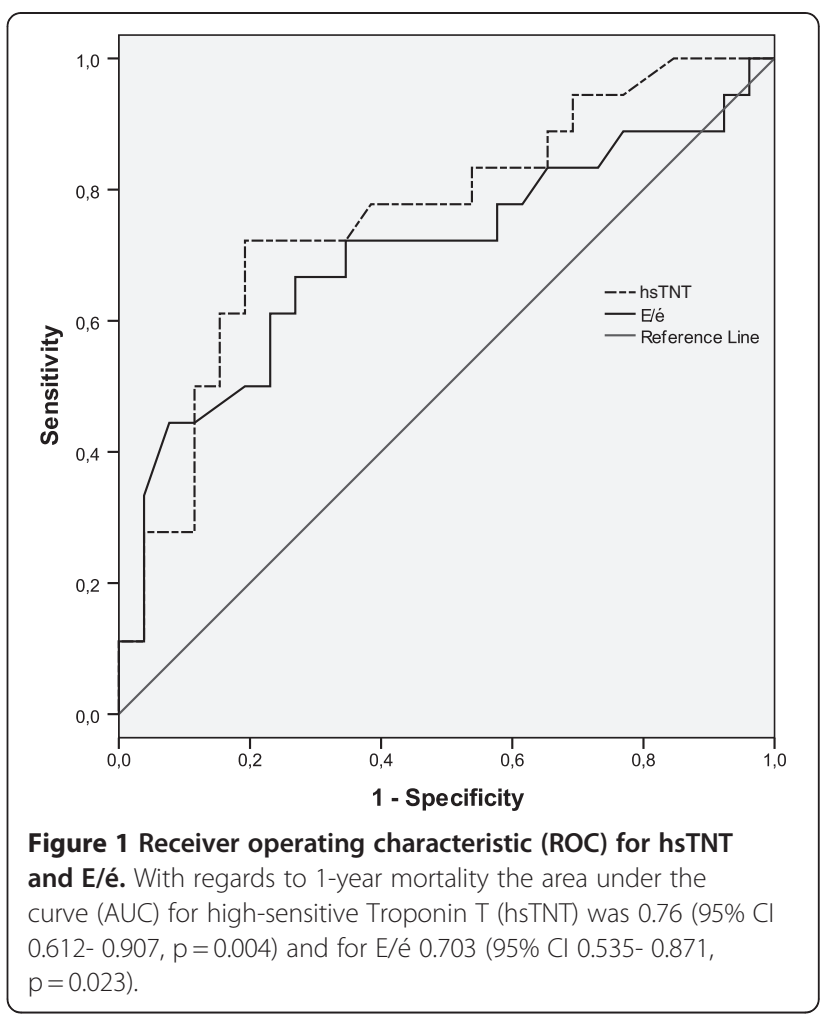

BNP ranged from 29 to $2031 \mathrm{pmol} / \mathrm{l}$ (median189 pmol/l [IQR 107-375]) (Table 1) and was elevated (>30 pmol/l) in $48(98 \%)$ patients. AUC for BNP was 0.603 (95\% CI 0.415 to $0.791, p=0.26$ ). hsTNT correlated with critical illness scores APACHE II $[\mathrm{r}=0.335, \mathrm{p}=0.019]$ and SOFA $[r=0.301, p=0.036]$. There was no significant association with BNP, age, gender, diabetes, previous cardiac disease, E/é, lactate levels or creatinine.

\section{Echocardiography}

A total of 46 echocardiographic examinations were available for analysis, since 3 examinations were lost during the installation of a new offline storage and analysis system. The intra- and interobserver variability for echocardiographic parameters of LV systolic function ranged from $3.1 \%$ to $9.9 \%$ as reported earlier [35] and for echocardiographic parameters of LV diastolic function from $3.2 \%$ to $9.6 \%$. There were no significant differences between survivors and non-survivors in any of the measured LV systolic function parameters (Table 2). The LV diastolic function parameters, E/é and La volume, surrogates of LV filling pressure, differed significantly between survivors and non-survivors (E/é median 9.9 vs 11.7, $\mathrm{p}=0.023$; La volume median $24 \mathrm{ml} / \mathrm{m} 2$ vs $31 \mathrm{ml} / \mathrm{m} 2$, $\mathrm{p}=0.024$ ) respectively (Table 2 ). In this study La volume was only feasible in 38 patients. Further, as La volume was less significant than E/é, E/é was chosen for further calculations. E/é correlated with age $(\mathrm{r}=0.474, \mathrm{p}=0.001)$. 
Table 1 Patient characteristics

\begin{tabular}{|c|c|}
\hline Variable & $n=49$ \\
\hline \multicolumn{2}{|l|}{ Demographics } \\
\hline Median age, $y$ & $65(54-74)$ \\
\hline Female sex & $14(29 \%)$ \\
\hline \multicolumn{2}{|l|}{ Previous medical history } \\
\hline Diabetes mellitus & $6(12 \%)$ \\
\hline Hypertension & $12(24 \%)$ \\
\hline Cardiac disease & $12(24 \%)$ \\
\hline Pre- existing therapy & $24(49 \%)$ \\
\hline \multicolumn{2}{|l|}{ Clinical data } \\
\hline APACHE ॥ & $24(19-29)$ \\
\hline SOFA score & $11(9-13)$ \\
\hline Mechanical ventilation, $\%$ & 90 \\
\hline \multicolumn{2}{|l|}{ Biochemical markers } \\
\hline Creatinine, $\mu \mathrm{mol} / \mathrm{l}$ & $155(92.0-231.0)$ \\
\hline Lactate, mmol// & $2.3(1.6-3.3)$ \\
\hline hsTNT, ng/l & $80(24.0-193.5)$ \\
\hline BNP, pmol// & $189(107-375)$ \\
\hline Echocardiographic data & $n=46$ \\
\hline LVEF,\% & $45(40-55)$ \\
\hline La volume, ml/m2 & $24(21.0-31.6)$ \\
\hline AVPDm, mm & $10.7(8.0-12.7)$ \\
\hline $\mathrm{E}, \mathrm{cm} / \mathrm{s}$ & $89(71-104)$ \\
\hline $\mathrm{A}, \mathrm{cm} / \mathrm{s}$ & $67(52-91)$ \\
\hline E/A & $1.3(0.9-1.5)$ \\
\hline $\mathrm{DT}, \mathrm{ms}$ & $165(148-200)$ \\
\hline TDIs, cm/s & $8.6(7.1-10.0)$ \\
\hline é, $\mathrm{cm} / \mathrm{s}$ & $8.4(7.1-10.0)$ \\
\hline á, $\mathrm{cm} / \mathrm{s}$ & $9(7.5-12.3)$ \\
\hline E/é & $10.1(8.5-12.2)$ \\
\hline LVOT VTI, cm & $17(15-23)$ \\
\hline \multicolumn{2}{|l|}{ Mortality } \\
\hline 7 day mortality, $\%$ & 16 \\
\hline 28 day mortality, $\%$ & 27 \\
\hline 1 year mortality, $\%$ & 37 \\
\hline ICU mortality, $\%$ & 27 \\
\hline
\end{tabular}

Data are presented as median (lower quartile- upper quartile) or in numbers (\%). APACHE II=Acute Physiology and Chronic Health Evaluation; SOFA=Sequential Organ Failure Assessment.

There was no significant association between E/é and hsTNT, APACHE II, SOFA, lactate, BNP, La volume, gender, diabetes or previous cardiac disease. E/é was under 8 in $18 \%$, between 8 and 15 in $71 \%$ and over 15 in $11 \%$ of patients. With regards to 1-year mortality, AUC for E/é was $0.703(95 \%$ CI $0.535-0.871, \mathrm{p}=0.023)$ with $72 \%$ sensitivity and $65 \%$ specificity for a cut-off value of 10.1 (Figure 1). The other LV diastolic function parameters did not differ significantly between survivors and non-survivors (Table 2).

\section{Predictors of 1 year-mortality}

Univariate analysis showed that hsTNT levels were significantly higher in non-survivors (median 168 [IQR 89.8-358] $\mathrm{ng} / \mathrm{l}$ ) than in survivors (median 60 [IQR 1799.5] ng/l), $\mathrm{p}=0.003$ while BNP was not significantly different $(\mathrm{p}=0.26)$. Other predictors identified by univariate analysis were APACHE II, SOFA, age and the LV diastolic function parameters E/é and La volume (Table 2). Out of 45 patients with TNT values $>14 \mathrm{ng} / \mathrm{l}\left(99^{\text {th }}\right.$ percentile), 18 (40\%) were non-survivors and 27 (60\%) were survivors. The remaining four patients with hsTNT $\leq 14 \mathrm{ng} / \mathrm{l}$ were all survivors.

A multivariable logistic regression analysis including hsTNT, APACHE II, E/é and age, identified hsTNT $(p=0.010)$ as the only independent predictor of 1-year mortality with an adjusted OR of 2.0 (95\% CI 1.2- 3.5). Logistic regression showed increasing odds ratios for mortality for increasing hsTNT quartiles (OR of 3.7 [95\% CI 0.3- 41.6], $\mathrm{p}=0.294$; OR of 9.4 [95\% CI 0.93 95.9], $\mathrm{p}=0.058$; OR of 22 [95\% CI 2.1- 236.1], $\mathrm{p}=0.011$ ). When we included SOFA score to the model it became unstable due to correlations between the explanatory variable SOFA score and APACHE. When including creatinine and pre-existing cardiac disease (including atrial fibrillation) as independent variables in the model this did not affect the model or contribute with any significance.

\section{Discussion}

The main findings of this study are: 1) hsTNT was the only independent predictor of 1 -year mortality after adjustment for other factors; 2) elevated levels of hsTNT were found in the majority of patients; 3) E/é was higher in non-survivors; 4) neither BNP nor echocardiographic LV systolic function parameters were predictive of 1-year mortality.

\section{Early elevation of hsTNT is an independent predictor of 1-year mortality in critically ill patients with shock}

Elevation of cTn is common among ICU patients for several reasons including myocardial infarction, sepsis and renal failure [41] and is known to be predictive of mortality during shorter follow-up periods such as ICUand hospital mortality [14,15,41-44]. Even in critically ill patients where coronary artery disease has been excluded, elevated cTn is known to be associated with increased mortality [16]. In medical ICU patients, elevated $\mathrm{cTn}$ measured within $12 \mathrm{~h}$ of admission has been shown to be an independent risk factor for 30-day and 2-year mortality after adjustment for severity of illness [42]. The recent introduction of a new generation of high sensitivity assays for cTn, with a lower detection limit and sufficient analytical precision [9,10], allows the detection of elevated $\mathrm{cTn}$ in a considerably higher 
Table 2 Patient characteristic according to 1-year survival

\begin{tabular}{|c|c|c|c|}
\hline Variable & $\begin{array}{c}\text { Survivors } \\
(n=31)\end{array}$ & $\begin{array}{l}\text { Non- survivors } \\
\quad(n=18)\end{array}$ & p \\
\hline \multicolumn{4}{|l|}{ Demographics } \\
\hline Median age, y & $60(49.5-68.5)$ & $72(68.3-76)$ & 0.031 \\
\hline Female sex & $10(32 \%)$ & $4(22 \%)$ & ns \\
\hline \multicolumn{4}{|c|}{ Previous medical history } \\
\hline Diabetes mellitus & $4(13 \%)$ & $2(11 \%)$ & ns \\
\hline Hypertension & $9(29 \%)$ & $3(17 \%)$ & ns \\
\hline Cardiac disease & $8(26 \%)$ & $4(22 \%)$ & ns \\
\hline Pre-existing therapy & $14(45 \%)$ & $10(56 \%)$ & ns \\
\hline \multicolumn{4}{|l|}{ Clinical data } \\
\hline APACHE ॥ & $22(16-26)$ & $28.5(21-34)$ & 0.009 \\
\hline SOFA score & $10(9-13)$ & $13(11-14)$ & 0.024 \\
\hline Mechanical ventilation & $29(94 \%)$ & $15(83 \%)$ & ns \\
\hline \multicolumn{4}{|l|}{ Biochemical markers } \\
\hline Creatinine, $\mu \mathrm{mol} / \mathrm{l}$ & $154(88-221)$ & $171(105-238)$ & ns \\
\hline Lactate, mmol/l & $2.2(1.6-3.2)$ & $2.5(1.7-4.4)$ & ns \\
\hline hsTNT, ng/l & $60(17.0-99.5)$ & $168(89.8-358)$ & 0.003 \\
\hline BNP, pmol// & $159(84-339)$ & $241(149-446)$ & 0.26 \\
\hline \multicolumn{4}{|c|}{ Echocardiographic data } \\
\hline & Survivors $(n=28)$ & Non- survivors $(n=18)$ & \\
\hline LVEF,\% & $48(40-55)$ & $45(36-65)$ & 0.87 \\
\hline La volume, $\mathrm{ml} / \mathrm{m} 2$ & $24(20-27)$ & $31(25-36)$ & 0.024 \\
\hline AVPD, mm & $11.5(8.8-13)$ & $9.0(7.5-11)$ & 0.087 \\
\hline $\mathrm{E}, \mathrm{cm} / \mathrm{s}$ & $83.5(68.8-96.3)$ & $102.5(75.5-113.0)$ & ns \\
\hline $\mathrm{A}, \mathrm{cm} / \mathrm{s}$ & $67.5(57.0-92.3)$ & $63.5(40.0-86.0)$ & ns \\
\hline $\mathrm{E} / \mathrm{A}$ & $1.2(0.85-1.4)$ & $1.4(1.0-1.9)$ & ns \\
\hline $\mathrm{DT}, \mathrm{ms}$ & $170(150-200)$ & 160 (135-195) & ns \\
\hline TDls, cm/s & $8.5(7.2-9.7)$ & $8.7(6.7-10)$ & ns \\
\hline é, $\mathrm{cm} / \mathrm{s}$ & $8.4(7.5-10.8)$ & $7.9(6.3-9.6)$ & ns \\
\hline á, $\mathrm{cm} / \mathrm{s}$ & $9.9(7.7-12.3)$ & $8.8(7.5-10)$ & ns \\
\hline$\overline{E / e ́}$ & $9.9(8.1-10.9)$ & $11.7(9.8-14.8)$ & 0.023 \\
\hline LVOT VTI, cm & $20(15-23)$ & $17(16-23)$ & 0.18 \\
\hline
\end{tabular}

Data are presented as median (lower quartile- upper quartile) or in numbers (\%).

frequency compared to earlier essays (97\% vs 76\%) in patients with cardiovascular disease $[10,11]$. In general, renal insufficiency and cardiologically ill populations, detectable levels of hsTnT are associated with adverse outcomes $[13,45,46]$. However in critically ill patients, information about the value of high sensitive cTn is scarce. In a study by Rosjö et al. [17], hsTNT on inclusion was detectable in all patients with sepsis and septic shock. Further, hsTNT correlated to severity of disease and was significantly higher in hospital non-survivors but could not be identified as an independent predictor of mortality. Reynolds et al. [15] showed that an increased cTnI concentration while in ICU was associated with increased mortality in hospital, after adjusting for admission characteristics, age, severity of illness at admission, organ support, and serum creatinine concentrations. These results are in line with our study, where hsTNT measured within $12 \mathrm{~h}$ was detectable in $100 \%$, elevated in $92 \%$ of patients, and correlated significantly with critical illness scores. Further, hsTNT was identified as the only independent predictor of even longer-term (1-year) mortality. The findings are strengthened by the increased odds ratios for mortality for increasing quartiles of hsTNT identified in this population although the wide CIs indicate that larger studies are needed to support our findings.

We also note that median hsTnT in non-survivors was higher in our study compared to the study by Rosjö et al.: 168 vs $54 \mathrm{ng} / \mathrm{l}$. As the frequency of cardiovascular disease was comparable in both studies (24\% and 26\% 
respectively) we speculate that this might be due to sicker patients in our non-survivor group (median SOFA 13 vs 9 in Rosjö et al.). Since this was an exploratory study, and due to the paucity of literature regarding accepted levels of hsTNT in the critically ill, we chose the cut-off level with the best balance of specificity and sensitivity. We do not know if this is adequate and we hope that future studies will inform us as to what to expect from different critically ill populations. We note that the cut-off point identified by our ROC analysis is much higher than that identified in non-critically ill patients. The reason for this and its relevance is unclear and deserves attention in future studies.

We investigated if there was a confounding relationship between hsTNT and pre-existing cardiac disease or renal insufficiency but found no significant association which is propably due to sample size. Additionally when entering these confounders into the multivariable model, hsTNT could still be identified as the sole significant predictor of mortality.

\section{Diastolic but not systolic function parameters are associated with mortality}

Impairment of myocardial function in patients with shock is often masked by concurrent elevations in cardiac index and a low systemic vascular resistance, making parameters such as LVEF often unreliable for monitoring LV systolic function and as a prognostic marker $[1,47]$. Additionally, markers of LV systolic function are frequently described to be normal or near normal $[3,4,24]$ in these patients. This is in line with our results, where all echocardiographic parameters of LV systolic function were normal or mildly reduced and none were predictive of 1-year mortality. LV diastolic dysfunction with increased filling pressures is known to be predictive of mortality in cardiac patients [30] but has shown conflicting results regarding prognosis in ICU patients $[3,4,24,25]$. In our study E/é and La volume, both surrogates of LV filling pressure, were predictive of mortality but other diastolic parameters were not. E/é did, as expected, correlate significantly with age but not with hsTNT, BNP, APACHE II, SOFA score or lactate. These results were to some extent unexpected, as E/é has been shown in previous studies to be correlated to the severity of critical illness $(3,47)$.

Recent studies allude to the importance of E/é to prognosis in critically ill patients with shock $[3,25]$. Sturgess et al. [25] identified E/é as an independent predictor of hospital mortality, although with a considerably higher cut-off value than in our study $(\mathrm{E} / \mathrm{e}=14.5)$. This might be attributable to a higher percentage of preexisting cardiac disease ( $43 \%$ in that study vs $24 \%$ in our study) and narrower inclusion criteria (septic shock vs shock). An É/é ratio $<8 \mathrm{~cm} / \mathrm{s}$ is usually associated with normal filling pressure and E/é ratio $>15 \mathrm{~cm} / \mathrm{s}$ commonly with increased filling pressure [30]. In our study median E/é was 10.1, thus representing a level between 8-15 where filling pressures might be elevated according to international guidelines [30]. Our study population represents a group of patients with increased age, preexisting cardiovascular disease as well as acute critical illness. All can affect diastolic function and thus filling pressures. As we do not know to what extent E/é is affected by either of these different entities, we cannot separate their cardiac effects. Although E/é was only mildly increased it was still predictive irrespective of the underlying cause.

\section{BNP is not a valuable marker of 1-year mortality in this population}

The role of natriuretic peptides as prognostic markers is well described in patients with cardiovascular disease [18]. Even in ICU patients several outcome studies refer to their usefulness $[21,22]$. Nevertheless the prognostic value of natriuretic peptides has been described as questionable [4], as they can be elevated due to a variety of reasons in critically ill patients [20]. Age, gender, preexisting or critical illness associated renal and myocardial impairment as well as inflammatory states such as sepsis or septic shock all affect BNP [20,22]. In our study, elevated BNP was seen in most patients (98\%) but did not correlate with critical illness (APACHE II) or organ dysfunction (SOFA), nor discriminated survivors from non-survivors. As LV systolic function overall was near normal and no patient had acute heart failure as the sole diagnosis, we speculate that elevated BNP due to other factors than heart failure is of little prognostic value.

\section{Limitations}

Our study group containing the sickest of ICU patients with hemodynamic instability, implying cardiovascular impairment, is prone to bias and our results could have been completely different in another set of ICU patients. Therefore there is a risk of bias that could have led to overestimation of the prognostic ability of hsTNT. We have not excluded patients with known heart failure or atrial fibrillation, nor have we excluded patients with new onset of atrial fibrillation during their critical illness, which might have influenced our results. We did not record the absence or presence of ischemic ECG changes. This could have been of additional value to the echocardiographic examination in interpreting the likely cause of hsTNT elevations although this was not the aim of this study. In this observational study our intention was to investigate a group of critically ill patients with shock knowing that increased age, the likelihood of pre-existing cardiovascular disease and critical 
illness induced cardiac abnormalities such as atrial fibrillation, ischemic and/or cardiomyopathy probably would influence our results. Excluding patients with preexisting cardiac disease would probably have reduced the cardiological impact of the regression model but would also have made the sample less representative of the population of critically ill patients. Since coronary angiography was not a possibility in this study, and since patients did not have pre-morbid echocardiograms, it is possible that we may have identified a subpopulation of critically ill patients with cardiac disease. We maintain however, that in this general group of very ill patients with shock, only hsTNT was indentified as a predictor of 1-year mortality, regardless of aetiology and background co-morbidity. A larger study stratifying BNP by age and gender might have yielded different results. TDI measurements were only done at the septal mitral annulus whereas current recommendations include both the septum and lateral wall [30]. Further a blinded assessment of echocardiographic data would have been desirable. Finally, the sample size is small; hence only limited variables could be used for the model, increasing the likelihood of confounding. We have attempted to reduce this by using univariate analysis to identify probable predictors, limiting the number of predictors and including these in the multivariate model. The results were congruent for different models that showed some consistency over the outcome predictor.

The strength of this study is that both LV systolic and diastolic echocardiographic measurements together with cardiac biomarkers were analysed as predictors of longer-term outcome.

\section{Conclusion}

In this observational, cohort study, we found that hsTNT seems to be important for prognosis in the critically ill. Although in our study early measurement of hsTNT correlated with critical illness scores and was identified as the only independent predictor of 1-year mortality, clinicians should be aware that studies as ours are explorative and the results should be interpreted cautiously. Future studies should inform us on the reproducibility of these results, what levels to expect in different critical care subpopulations, what decision limits to implement and their clinical significance.

\section{Competing interests}

The authors declare that they have no competing interests.

\section{Authors' contributions}

$L B, R W, M C, P G, J D$ have made substantial contributions to conception and design of the study. $\mathrm{LB}, \mathrm{MC}$ and $\mathrm{HO}$ participated in interpretation of data, helped to draft the manuscript. JD made contributions acquisition of data. $P G, L B, M C$ made substantial contributions in acquisition and analysis of data. All authors have made substantial intellectual contributions to the manuscript and have given final approval of the version to be published. All authors read and approved the final manuscript.

\section{Acknowledgements}

The authors thank Nuray Güner for statistical advice. Supported by grants from Anna-Lisa and Sven Eriks Lundgren's Foundation, Acta Foundation and the Region Skane County Council, Sweden. None of the funding agents were involved in study design, data collection, analysis and interpretation, and in writing and submitting the manuscript.

\section{Author details}

${ }^{1}$ Department of Anaesthesiology and Intensive Care, Institution of Clinical Sciences, Skåne University Hospital, Lund University, Inga Marie Nilssons gata 47, S-20502 Malmö, Sweden. ${ }^{2}$ Department of Cardiology, Institution of Clinical Sciences, Skåne University Hospital, Lund University, Getingevägen 4, S- 22185 Lund, Sweden. ${ }^{3}$ Department of Biomedical Science, Malmö University, Södra Förstadsgatan 101, S- 20506 Malmö, Sweden. ${ }^{4}$ Department of Anaesthesiology and Intensive Care, Institution of Clinical Sciences, Skåne University Hospital, Lund University, Inga Marie Nilssons gata 47, S-20502 Malmö, Sweden. ${ }^{5}$ Heart Health Group, Lund University, Geijersg. 4C, 21618 Limhamn, Sweden. ${ }^{6}$ Department of Anaesthesiology and Intensive Care, Institution of Clinical Sciences, Skåne University Hospital, Lund University, Inga Marie Nilssons gata 47, S-20502 Malmö, Sweden.

Received: 28 February 2012 Accepted: 17 September 2012 Published: 24 September 2012

\section{References}

1. Parker MM, Shelhamer JH, Bacharach SL, Green MV, Natanson C, Frederick TM, Damske BA, Parrillo JE: Profound but reversible myocardial depression in patients with septic shock. Ann Intern Med 1984, 100(4):483-490.

2. Ellrodt AG, Riedinger MS, Kimchi A, Berman DS, Maddahi J, Swan HJC, Murata GH: Left ventricular performance in septic shock: reversible segmental and global abnormalities. Am Heart J 1985, 110(2):402-409.

3. Ikonomidis I, Nikolaou M, Dimopoulou I, Paraskevaidis I, Lekakis J, Mavrou I, Tzanela M, Kopterides P, Tsangaris I, Armaganidis A, et al: Association of left ventricular diastolic dysfunction with elevated NT-pro-BNP in general intensive care unit patients with preserved ejection fraction: a complementary role of tissue Doppler imaging parameters and NT-proBNP levels for adverse outcome. Shock 2010, 33(2):141-148.

4. McLean AS, Huang SJ, Hyams S, Poh G, Nalos M, Pandit R, Balik M, Tang B, Seppelt I: Prognostic values of B-type natriuretic peptide in severe sepsis and septic shock. Crit Care Med 2007, 35(4):1019-1026.

5. Thygesen K, Mair J, Katus H, Plebani M, Venge P, Collinson P, Lindahl B, Giannitsis E, Hasin Y, Galvani M, et al: Recommendations for the use of cardiac troponin measurement in acute cardiac care. Eur Heart J 2010, 31(18):2197-2204.

6. Poelaert J, Declerck C, Vogelaers D, Colardyn F, Visser CA: Left ventricular systolic and diastolic function in septic shock. Intensive Care Med 1997, 23(5):553-560.

7. Munt B, Jue J, Gin K, Fenwick J, Tweeddale M: Diastolic filling in human severe sepsis: an echocardiographic study. Crit Care Med 1998, 26(11):1829-1833.

8. Bouhemad B, Nicolas-Robin A, Arbelot C, Arthaud M, Feger F, Rouby JJ: Acute left ventricular dilatation and shock-induced myocardial dysfunction. Crit Care Med 2009, 37(2):441-447.

9. Thygesen K, Alpert JS, White HD, Jaffe AS, Apple FS, Galvani M, Katus HA Newby LK, Ravkilde J, Chaitman B, et al: Universal definition of myocardial infarction. Circulation 2007, 116(22):2634-2653.

10. Giannitsis E, Kurz K, Hallermayer K, Jarausch J, Jaffe AS, Katus HA: Analytical validation of a high-sensitivity cardiac troponin T assay. Clin Chem 2010, 56(2):254-261.

11. Weber M, Bazzino O, Navarro Estrada JL, de Miguel R, Salzberg S, Fuselli J, Liebetrau C, Woelken M, Moellmann H, Nef H, et al: Improved diagnostic and prognostic performance of a new high-sensitive troponin T assay in patients with acute coronary syndrome. Am Heart J 2011, 162(1):81-88.

12. Bonaca M, Scirica B, Sabatine M, Dalby A, Spinar J, Murphy SA, Jarolim P, Braunwald E, Morrow DA: Prospective evaluation of the prognostic implications of improved assay performance with a sensitive assay for cardiac troponin I. J Am Coll Cardiol 2010, 55(19):2118-2124.

13. de Lemos JA, Drazner MH, Omland T, Ayers CR, Khera A, Rohatgi A, Hashim I, Berry JD, Das SR, Morrow DA, et al: Association of troponin T detected 
with a highly sensitive assay and cardiac structure and mortality risk in the general population. JAMA 2010, 304(22):2503-2512.

14. Lim W, Qushmaq I, Devereaux PJ, Heels-Ansdell D, Lauzier F, Ismaila AS, Crowther MA, Cook DJ: Elevated cardiac troponin measurements in critically ill patients. Arch Intern Med 2006, 166(22):2446-2454.

15. Reynolds T, Cecconi M, Collinson P, Rhodes A, Grounds RM, Hamilton MA: Raised serum cardiac troponin I concentrations predict hospital mortality in intensive care unit patients. Br J Anaesth 2012, 109(2):219-224.

16. Ammann $\mathrm{P}$, Maggiorini $\mathrm{M}$, Bertel $\mathrm{O}$, Haenseler $\mathrm{E}$, Joller-Jemelka HI, Oechslin E, Minder El, Rickli H, Fehr T: Troponin as a risk factor for mortality in critically ill patients without acute coronary syndromes. J Am Coll Cardiol 2003, 41(11):2004-2009.

17. Rosjo H, Varpula M, Hagve TA, Karlsson S, Ruokonen E, Pettila V, Omland T: Circulating high sensitivity troponin $\mathrm{T}$ in severe sepsis and septic shock: distribution, associated factors, and relation to outcome. Intensive Care Med 2011, 37(1):77-85.

18. de Lemos JA, McGuire DK, Drazner MH: B-type natriuretic peptide in cardiovascular disease. Lancet 2003, 362(9380):316-322.

19. Alehagen U, Lindstedt G, Levin LA, Dahlstrom U: Risk of cardiovascular death in elderly patients with possible heart failure. B-type natriuretic peptide (BNP) and the aminoterminal fragment of ProBNP (N-terminal proBNP) as prognostic indicators in a 6-year follow-up of a primary care population. Int J Cardiol 2005, 100(1):125-133.

20. Omland T: Advances in congestive heart failure management in the intensive care unit: B-type natriuretic peptides in evaluation of acute heart failure. Crit Care Med 2008, 36(1 Suppl):S17-S27.

21. Almog Y, Novack V, Megralishvili R, Kobal S, Barski L, King D, Zahger D: Plasma level of $\mathrm{N}$ terminal pro-brain natriuretic peptide as a prognostic marker in critically ill patients. Anesth Analg 2006, 102(6):1809-1815.

22. Tung RH, Garcia C, Morss AM, Pino RM, Fifer MA, Thompson BT, Lewandrowski K, Lee-Lewandrowski E, Januzzi JL: Utility of B-type natriuretic peptide for the evaluation of intensive care unit shock. Crit Care Med 2004, 32(8):1643-1647.

23. Cholley BP, Vieillard-Baron A, Mebazaa A: Echocardiography in the ICU: time for widespread use! Intensive Care Med 2006, 32(1):9-10

24. Sturgess DJ, Marwick TH, Joyce CJ, Jones M, Venkatesh B: Tissue Doppler in critical illness: a retrospective cohort study. Crit Care 2007, 11(5):R97.

25. Sturgess DJ, Marwick TH, Joyce C, Jenkins C, Jones M, Masci P, Stewart D, Venkatesh B: Prediction of hospital outcome in septic shock: a prospective comparison of tissue Doppler and cardiac biomarkers. Crit Care 2010, 14(2):R44.

26. Willenheimer R, Cline C, Erhardt L, Israelsson B: Left ventricular atrioventricular plane displacement: an echocardiographic technique for rapid assessment of prognosis in heart failure. Heart 1997, 78(3):230-236.

27. Jensen-Urstad K, Bouvier F, Hojer J, Ruiz H, Hulting J, Samad B, Thorstrand C, Jensen-Urstad M: Comparison of different Echocardiographic methods with radionuclide imaging for measuring left ventricular ejection fraction during acute myocardial infarction treated by thrombolytic therapy. Am J Cardiol 1998, 81(5):538-544.

28. Nikitin NP, Witte KKA: Application of tissue Doppler imaging in cardiology. Cardiology 2004, 101(4):170-184.

29. Thomas DE, Yousef ZR, Fraser AG: A critical comparison of echocardiographic measurements used for optimizing cardiac resynchronization therapy: stroke distance is best. Eur J Heart Fail 2009, 11(8):779-788

30. Nagueh SF, Appleton CP, Gillebert TC, Marino PN, Oh JK, Smiseth OA, Waggoner AD, Flachskampf FA, Pellikka PA, Evangelista A: Recommendations for the evaluation of left ventricular diastolic function by echocardiography. J Am Soc Echocardiogr 2009, 22(2):107-133.

31. Dellinger RP, Carlet JM, Masur H, Gerlach H, Calandra T, Cohen J, Gea-Banacloche J, Keh D, Marshall JC, Parker MM, et al: Surviving sepsis campaign guidelines for management of severe sepsis and septic shock. Crit Care Med 2004, 32(3):858-873.

32. Chew MS, Ihrman L, During J, Bergenzaun L, Ersson A, Unden J, Ryden J,

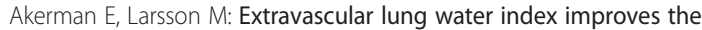
diagnostic accuracy of lung injury in patients with shock. Crit Care 2012, 16(1):R1

33. Knaus WA, Draper EA, Wagner DP, Zimmerman JE: Prognosis in acute organ-system failure. Ann Surg 1985, 202(6):685-693.
34. Vincent $J L$, de Mendonca A, Cantraine F, Moreno R, Takala J, Suter PM, Sprung CL, Colardyn F, Blecher S: Use of the SOFA score to assess the incidence of organ dysfunction/failure in intensive care units: results of a multicenter, prospective study. Working group on "sepsis-related problems" of the European Society of Intensive Care Medicine. Crit Care Med 1998, 26(11):1793-1800.

35. Bergenzaun L, Gudmundsson P, Ohlin H, During J, Ersson A, Ihrman L, Willenheimer R, Chew M: Assessing left ventricular systolic function in shock: evaluation of echocardiographic parameters in intensive care. Crit Care 2011, 15(4):R200

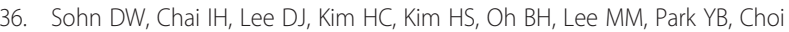
YS, Seo JD, et al: Assessment of mitral annulus velocity by Doppler tissue imaging in the evaluation of left ventricular diastolic function. J Am Coll Cardiol 1997, 30(2):474-480.

37. Lester SJ, Ryan EW, Schiller NB, Foster E: Best method in clinical practice and in research studies to determine left atrial size. Am J Cardiol 1999, 84(7):829-832.

38. Bewick V, Cheek L, Ball J: Statistics review 14: logistic regression. Crit Care 2005, 9(1):112-118

39. Greenland S: Modeling and variable selection in epidemiologic analysis. Am J Public Health 1989, 79(3):340-349.

40. Strand $\mathrm{K}$, Flaatten $\mathrm{H}$ : Severity scoring in the ICU: a review. Acta Anaesthesiol Scand 2008, 52(4):467-478.

41. Lim W, Whitlock R, Khera V, Devereaux PJ, Tkaczyk A, Heels-Ansdell D, Jacka $M$, Cook D: Etiology of troponin elevation in critically ill patients. J Crit Care 2010, 25(2):322-328.

42. Babuin L, Vasile VC, Rio Perez JA, Alegria JR, Chai HS, Afessa B, Jaffe AS: Elevated cardiac troponin is an independent risk factor for short- and long-term mortality in medical intensive care unit patients. Crit Care Med 2008, 36(3):759-765.

43. Mehta NJ, Khan IA, Gupta V, Jani K, Gowda RM, Smith PR: Cardiac troponin I predicts myocardial dysfunction and adverse outcome in septic shock. Int J Cardiol 2004, 95(1):13-17.

44. Wu TT, Yuan A, Chen CY, Chen WJ, Luh KT, Kuo SH, Lin FY, Yang PC: Cardiac troponin I levels are a risk factor for mortality and multiple organ failure in noncardiac critically ill patients and have an additive effect to the APACHE II score in outcome prediction. Shock 2004, 22(2):95-101.

45. Twerenbold R, Jaffe A, Reichlin T, Reiter M, Mueller C: High-sensitive troponin T measurements: what do we gain and what are the challenges? Eur Heart J 2012, 33(5):579-586.

46. McGill D, Talaulikar G, Potter JM, Koerbin G, Hickman PE: Over time, high-sensitivity TnT replaces NT-proBNP as the most powerful predictor of death in patients with dialysis-dependent chronic renal failure. Clin Chim Acta 2010, 411(13-14):936-939.

47. Jardin F, Fourme T, Page B, Loubieres Y, Vieillard-Baron A, Beauchet A Bourdarias JP: Persistent preload defect in severe sepsis despite fluid loading: A longitudinal echocardiographic study in patients with septic shock. Chest 1999, 116(5):1354-1359.

doi:10.1186/1471-2253-12-25

Cite this article as: Bergenzaun et al.: High-sensitive cardiac Troponin T is superior to echocardiography in predicting 1-year mortality in patients with SIRS and shock in intensive care. BMC Anesthesiology 2012 12:25.

\section{Submit your next manuscript to BioMed Central and take full advantage of:}

- Convenient online submission

- Thorough peer review

- No space constraints or color figure charges

- Immediate publication on acceptance

- Inclusion in PubMed, CAS, Scopus and Google Scholar

- Research which is freely available for redistribution 